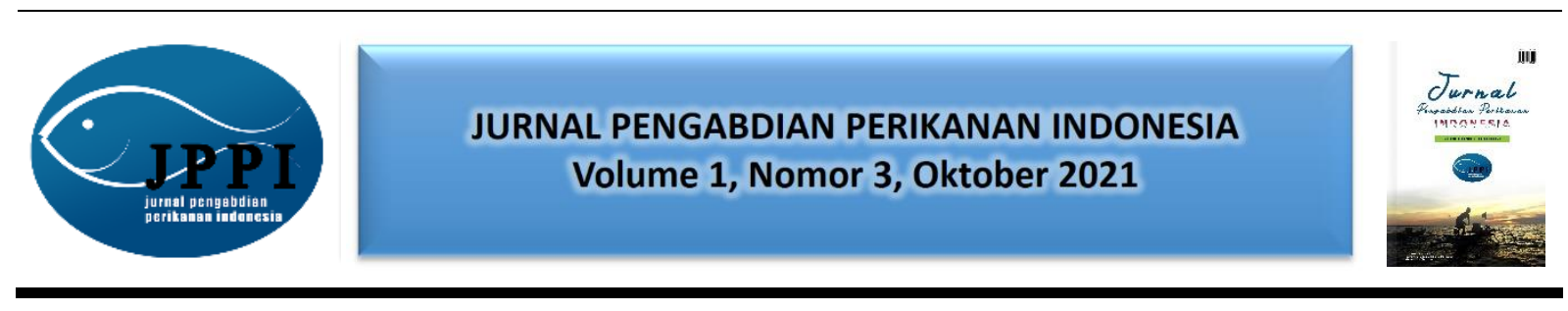

\title{
PENGEMBANGAN TEKNOLOGI MESIN PAKAN IKAN OTOMATIS (FISH AUTO FEEDER) DENGAN SISTEM TIMER LISTRIK
}

\author{
Fariq Azhar ${ }^{1}$, Alis Muklis ${ }^{1}$, Dewi Nura'eni Setyowati ${ }^{1}$, Salnida Yuniarti Lumbessy ${ }^{1}$, Dewi Putri \\ Lestari $^{1}$
}

${ }^{1}$ Program Studi Budidaya Perairan Universitas Mataram

Jalan Pendidikan Nomor 37 Kota Mataram

*Alamat korespondensi : fariqazhar@unram.ac.id

(Tanggal Submission: : 5 November 2021, Tanggal Accepted : 31 Oktober 2021)

\begin{abstract}
Keyword: Abstrak :
Budidaya, Permaslahan yang ditemui pada mitra usaha Milenial Jaya pada kegiatan penyuluhan ini Pakan, Fish adalah dalam pemberian pakan, para pembudidaya masih menebar pakan secara manual Auto dan tidak tidak berpatokan pada waktu makan dan laju pengosongan lambung ikan. Feeder Tujuan dari kegiatan pengabdian ini adalah memperkenalkan mesin pakan ikan otomatis yang dapat membantu memudahkan para pembudidaya dalam memberikan pakan pada ikan. Metode yang digunakan pada kegiatan ini menggunakan metode Focus Group Discussion (FGD) dengan menyampaikan informasi kepada pembudidaya terkait teknologi mesin pakan ikan otomatis (Fish Auto Feeder) dengan sistem timer listrik dan demonstrasi pengoprasian teknologi mesin pakan ikan otomatis. Hasil dari kegiatan pengabdian ini cukup baik yakni masyarakat cukup antusias dan tertarik dengan kegiatan penyuluhan yang dilakukan, hal tersebut terlihat dari banyaknya peserta yang hadir dan bertanya terkait mesin pakan yang didemonstrasikan. Dari kegiatan penyuluhan dapat membantu pembudidaya dalam memanajemen pemberian pakan secara efektif menggunakan teknologi modern yang dapat memperbaiki dan meningkatkan mutu kualitas produk budidaya mitra usaha Milenial Jaya di Desa Gontoran Kecamatan Lingsar.
\end{abstract}

Panduan Sitasi (APPA $7^{\text {th }}$ edition):

Azhar, F., Muklis, A., Setyowati, D. N., Lumbessy, D. N., Lestari, D. P. (2021). Pengembangan Teknologi Mesin Pakan Ikan Otomatis (Fish Auto Feeder) Dengan Sistem Timer Listrik. Jurnal Pengabdian Perikanan Indonesia, 1 (3), 248-253. http://doi.org/ 10.29303/jppi.v1i3.444

\section{PENDAHULUAN}

Desa Gontoran Kecamatan Lingsar merupakan salah satu kecamatan di Kabupaten Lombok Barat yang termasuk daerah yang memiliki ketersediaan air yang cukup melimpah, dan rata-rata mayoritas matapencaharian masyarakatnya berprofesi sebagai petani dan pembudidaya ikan. Dari hasil survey yang dilakukan di desa Gontoran Kecamatan Lingsar, terdapat beberapa kelompok usaha 
budidaya perikanan yang dibentuk oleh masyarakat, salah satunya adalah kelompok usaha Milenial Jaya yang terdiri dari 15 kepala keluarga dan sudah berdiri sejak tahun 2015. Dari hasil wawancara yang telah dilakukan dengan anggota kelompok tersebut, diketahui bahwa kendala yang dihadapi para pembudidaya adalah tingginya biaya dalam proses produksi dibandingkan dengan hasil produksi. Sekitar $60 \%$ biaya produksi dihabiskan untuk pengadaan pakan ikan yang berprotein tinggi. Hal tersebut sejalan dengan pernyataan Yusuf (2018), yang menyatakan bahwa produktivitas kegiatan budidaya sangat dipengaruhi oleh ketersediaan pakan yang cukup, sekitar 60\%-70\% dari total biaya produksi terletak pada pengadaan pakan.

Sementara itu, dalam kegiatan budidaya secara umum proses pemberian pakan ikan rata-rata masih menggunakan metode konvensional dengan cara memberi pakan secara manual dengan metode melontarkan atau menaburkan pakan menggunakan tangan. Metode tersebut tidak efektif dan efisien digunakan dalam budidaya sekala besar. Prijatna (2018), mengungkapkan bahwa, kekurangan dari pemberian pakan dengan cara manual membutuhkan ketepatan waktu dan kedisiplinan dari pembudidaya. Ayub et al., (2015), mengungkapkan bahwa ketepatan waktu dalam pemberian pakan sangat berpengaruh pada pertumbuhan ikan. Selain itu, kekurangan dari pemberian pakan dengan cara manual adalah para pembudidaya seringkali tidak memperhatikan takaran jumlah pakan yang diberikan. Erlania (2010), mengungkapkan bahwa apabila ada keterlambatan atau kekurangan pakan pada ikan akan berdampak pada pertumbuhan ikan yang lambat, sedangkan sebaliknya apabila pemberian pakan berlebihan akan berdampak pada pengendapan pakan di dasar kolam yang dapat mempengaruhi kualitas air dan berdampak pada kesehatan ikan.

Oleh karena itu, metode dalam pemberian pakan harus diperbaharui dengan memepertimbangkan ketepatan waktu pemberian pakan dan jumlah pakan yang akan diberikan. Pada pengabdian ini, kami mengembangkan suatu teknologi mesin pakan yang dirancang menggunakan sistem timer listrik yang dapat melontarkan pakan secara otomatis.

Kelompok usaha Milenial Jaya sudah berdiri sejak tahun 2015 dengan beranggotakan 15 orang kepala keluarga. Kelompok usaha budidaya ikan ini berfokus pada kegiatan pembesaran ikan. Dari kegiatan wawancara yang telah dilakukan kepada para pembudidaya diketahui bahwa kendala yang dihadapi dalam proses budidaya adalah sekitar $60 \%$ total biaya produksi dihabiskan untuk pengadaan pakan ikan namun hasil produksi belum dapat dikatakan bisa mensejahterakan kehidupan para pembudidaya. Dalam pemberian pakan, para pembudidaya masih menggunakan metode konvensional yakni dengan cara menebar pakan secara manual. Pemberian pakan juga tidak berpatokan pada waktu makan dan laju pengosongan lambung ikan, sehingga pemberian pakan dengan metode ini tidaklah efisien. Jika waktu pemberian pakan ikan tidak diperhatikan dengan benar dapat mengakibatkan banyaknya pakan yang terbuang karena ikan belum lapar saat diberikan pakan atau akan terjadi kanibalisme pada saat ikan terlambat diberikan pakan. Ikan memiliki memori dalam menerima pakan, sehingga waktu pemberian pakan dan lokasi atau titik pemberian pakan harus tetap. Hal tersebut akan membantu mengoptimalkan pertumbuhan dan bobot ikan, sehingga dapat menghasilkan ikan budidaya dengan kualitas yang bagus yang dapat mempengaruhi harga pasar.

\section{METODE KEGIATAN}

Kegiatan penyuluhan ini dilaksanakan pada bulan Oktober 2021 bertempat di desa Gontoran Kecamatan Lingsar, Kabupaten Lombok Barat Nusa Tenggara Barat. Penyuluhan dilaksanakan dengan menyampaikan informasi secara FGD (Focus Group Discusion) dan demonstrasi terkait pengembangan teknologi mesin pakan ikan otomatis (Fish Auto Feeder) dengan sistem timer listrik. 


\section{Penyuluhan program}

Kegiatan penyuluhan dilakukan dengan koordinasi dan sosialisasi pada kelompok sasaran yakni kelompok usaha Milenial Jaya. Penyuluhan program ini dilaksanakan untuk memberikan pengetahuan kepada para pembudidaya atau kelompok sasaran mengenai teknologi mesin pakan ikan otomatis (Fish Auto Feeder) dengan sistem timer listrik, dengan harapan agar sasaran kelompok memiliki pengetahuan yang cukup terkait program ini sehingga program ini dapat berjalan dengan baik dan lancar.

\section{Pelatihan Program}

Pelatihan dilaksanakan dengan memberikan informasi atau wawasan kepada pembudidaya dengan penekanan pada model komunikasi dua arah dengan pola tukar menukar pengalaman, diskusi kelompok, dan demonstrasi serta mempraktikkan penggunaan teknologi mesin pakan otomatis.

\section{Persiapan dan Pembuatan teknologi mesin pakan ikan otomatis (Fish Auto Feeder) dengan sistem timer listrik}

Mesin pakan ikan otomatis ini dirancang menggunakan 4 sistem timer dan 1 timer theben yang digunakan sebagai pengatur jadwal keluarnya pakan serta 3 unit timer switch yang digunakan untuk menghidupkan motor listrik sebagai penggerak blower yang akan mengeluarkan pakan dari mesin ke kolam. Mesin ini dirancang dengan sistem arduino yang terkoneksi dengan internet dan sistem kontrolnya melalui aplikasi di handphone dan ada juga secara manual di mesin tersebut.

\section{Pembinaan dan Pendampingan}

Pada program pembinaan dan pendampingan, kelompok sasaran dibina secara intensif oleh para tim penyuluhan mulai dari proses pembuatan mesin pakan ikan, hingga evaluasi keefektifan penggunaannya. Pembinaan ini bertujuan untuk membantu memecahkan masalah-masalah yang terjadi selama kegiatan baik masalah teknis maupun masalah manajemen kelompok.

\section{HASIL DAN PEMBAHASAN}

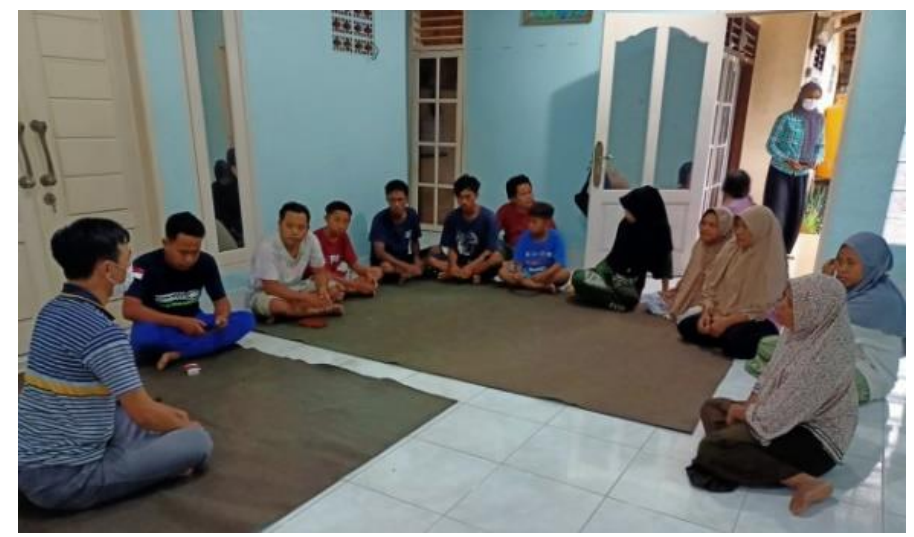

Gambar 1. (Kegiatan diskusi, Sumber : Dokumentasi pribadi 2021)

Kegiatan penyuluhan mengenai pengembangan teknologi mesin pakan ikan otomatis (fish auto feeder) dengan sistem timer listrik di desa Desa Gontoran Kecamatan Lingsar Kabupaten Lombok Barat berjalan dengan lancar, masyarakat cukup antusisas dengan kegiatan penyuluhan ini, terlihat dari banyaknya peserta yang hadir mengikuti kegiatan dan ikut menyaksikan proses uji coba teknologi mesin pakan ikan di kolam salah satu peserta budidaya. Penyuluhan ini dilakukan dengan mengumpulkan para peserta yang merupakan pembudidaya ikan nila kelompok usaha Milenial Jaya. 
Informasi yang diberikan kepada pembudidaya dilakukan dengan metode Focus Group Discussion (FGD) dengan memberikan informasi atau wawasan kepada pembudidaya dengan penekanan pada model komunikasi dua arah dengan pola tukar menukar pengalaman, diskusi kelompok, dan demonstrasi penggunaan teknologi mesin pakan ikan otomatis (Gambar 1).

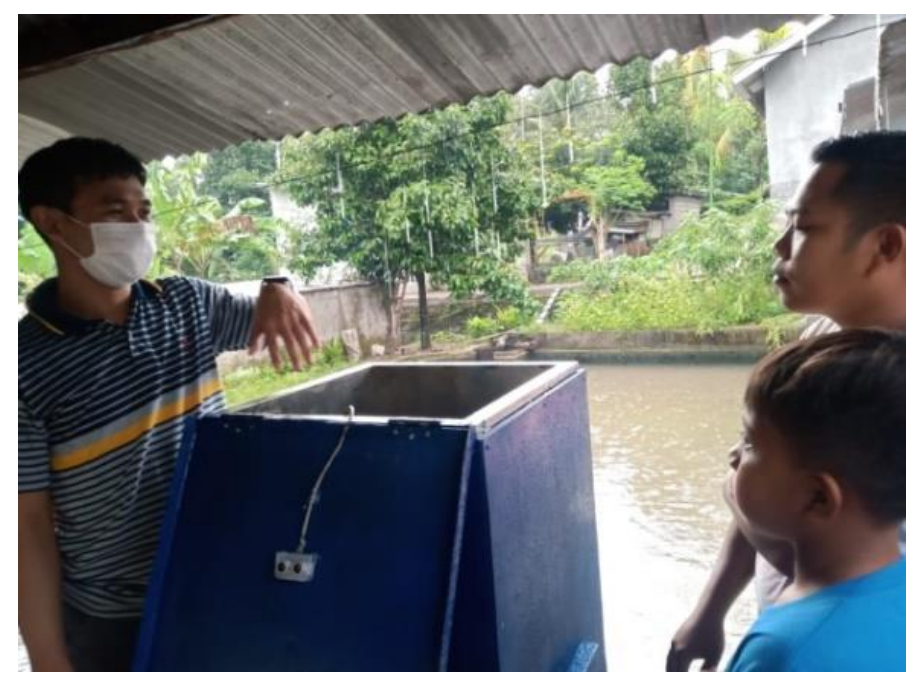

Gambar 2. (Demonstrasi alat, Sumber : Dokumentasi Pribadi, 2021)

Setelah diskusi, kegiatan penyuluhan dilanjutkan dengan kegiatan demonstrasi alat yang dilakukan di salah satu kolam milik pembudidaya dari kelompok usaha Milenial Jaya (Gambar 2). Pada kegiatan demonstrasi ini dijelaskan mekanisme kerja alat kepada seluruh peserta, hasil dari kegiatan demonstrasi ini, para pembudidaya banyak yang tertarik dengan mengajukan berbagai macam pertanyaan dari mulai cara kerja, kelemahan dan kelebihan dari alat ini.

Hasil dari kegiatan pemberian pakan ikan otomatis dapat membantu dalam mewujudkan usaha manajemen pemberian pakan secara efektif, karena pada mesin pakan ikan ini terdapat teknologi yang disambungkan melalui aplikasi di hanphone yang terhubung dengan internet untuk mengontrol mesin pakan (on/off) dan pengaturan waktu kapan akan dilakukan pemberian pakan pada ikan. Teknologi ini cukup menguntungkan bagi para pembudidaya ikan, karena dapat mengurangi kelalaian dalam pemberian pakan dan dapat mempermudah para pembudidaya ikan apabila ada kendala hujan saat waktu pemberian pakan. Hal yang harus diperhatikan dalam memberikan pakan pada ikan adalah frekuensi pemberian pakan yang dapat berpengaruh langsung pada pertumbuhan ikan, jumlah pakan yang diberikan tidak tepat dapat menyebabkan banyaknya pakan yang tidak dimakan oleh ikan dan terbuang yang berakibat pada buruknya kualitas air dan kondisi kesehatan ikan sehingga dapat menimbulkan kerugian bagi para pembudidaya secara signifikan. Selain itu, Menurut Subandiyono (2011), hal yang harus diperhatikan dalam memberikan pakan adalah laju pengosongan lambung pada ikan karena masing-masing ikan memiliki tingkat laju pengosongan lambung yang berbeda. Kemudian Wardhani et al., (2011) juga berpendapat bahwa pemilihan pakan untuk ikan air tawar harus mempertimbangkan kecernaan pakan pada ikan. 


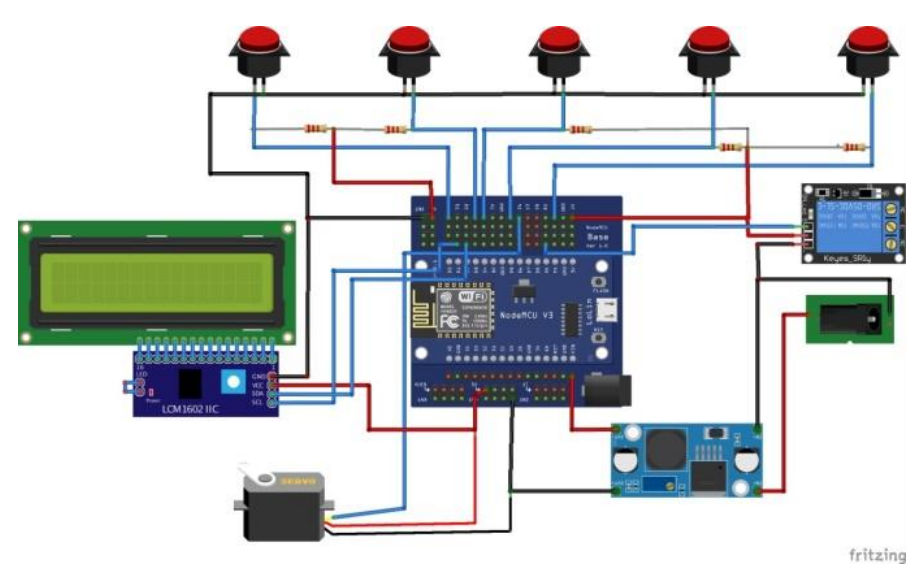

Gambar 3. Sistem arduino (Sumber : Dokumentasi pribadi, 2021)

Rancangan alat ini menggunakan sistem Arduino sebagai kontroler utama (Gambar 3), blower sebagai pelontar pakan, dan Aplikasi di handphone untuk mengatur jadwal makan ikan yang terkoneksi dengan internet. Sistem arduino terdiri dari perangkat hardware dan sebuah software Integrated Development Environment (IDE) sebagai bahasa pemrograman, selanjutnya akan dicompile menjadi kode biner dan diupload ke dalam memory Mikrokontroler, yang dapat dihubungkan ke komputer dan dapat menggunakan batrai (Adriansyah dan Oka, 2013). Sementara itu Fungsi blower pada alat ini adalah untuk mendorong pakan ikan agar terlontar ke arah kolam. Mesin pakan ini dirancang dengan sederhana agar mudah untuk dioprasikan oleh siapa saja. Cara kerjanya dapat dilakukan dengan mengatur waktu pemberian pakan pada aplikasi di handphone dengan bantuan internet dapat terkoneksi dengan mesin pakan tersebut. Ketika mesin diaktifkan melalui aplikasi sistem kontroler akan mengaktifkan motor DC yang akan menggerakkan blower ke posisi $0^{\circ}$. Kemudian sistem motor yang terdapat di tangki pakan akan membuka katup untuk menjatuhkan pakan ke arah blower sehingga pakan terlontar ke arah kolam ikan. Selanjutnya pakan akan disebar ke arak kolam, kemudian katup akan tertutup dan motor DC bergerak ke posisi $15^{\circ}$ ke atas. Begitu seterusnya sampai blower mencapai sudut $45^{\circ}$, kemudian posisi sudut blower akan dikembalikan ke posisi $0^{\circ}$. Perubahan derajat peniupan pakan tersebut menentukan persebaran pakan di kolam dan pertumbuhan ikan dalam satu kolam juga merata (Emmanuel dan Anyadike, 2013). Keuntungan dari penggunaan mesin pakan ini adalah terkontrolnya frekuensi pemberian pakan pada ikan. Menurut Subandiyono (2014), frekuensi pemberian pakan yaitu berapa kali pakan diberikan dalam satu hari pada ikan.

\section{KESIMPULAN DAN SARAN}

Kegiatan penyuluhan dapat membantu pembudidaya dalam memanajemen pemberian pakan secara efektif menggunakan teknologi modern yang dapat memperbaiki dan meningkatkan mutu kualitas produk budidaya mitra usaha Milenial Jaya di Desa Gontoran Kecamatan Lingsar.

Adapun saran untuk kegiatan pengabdian kedepannya diharapkan teknologi mesin pakan ikan otomatis dapat dikembangkan dan digunakan untuk meningkatkan kualitas produk budidaya.

\section{UCAPAN TERIMA KASIH}

Terima kasih kepada LPPM Universitas Mataram yang telah mewadahi dan membiayai kegiatan pengabdian ini. 


\section{DAFTAR PUSTAKA}

Adriansyah, A., \& Oka, H. (2013). Rancangan Bangun Prototife Elevator Menggunakan Microcontroller Arduino Atmega 328P. Jurnal Teknologi Elektro, 4(3). 100-112.

Ayub, M.A., Kushaini, S. and Amir, A. (2015). A new mobile robotic system for intensive aquaculture industries. Journal of Applied Science and Agriculture, 10(8). 1-7.

Emmanuel, O., Anyadike, C. (2013). Development of an Automatic Fish Feeder, Paper, Department of Agricultural and Bioresources Engineering, University of Nigeria Nsukka.

Erlania, R., A. B. Prasetio dan J. Haryadi. (2010). Dampak Manajemen Pakan dari Kegiatan Budidaya Ikan Nila (Oreochromis niloticus) di Keramba Jaring Apung terhadap Kualitas Perairan Danau Maninjau. J. Prosiding Forum Inovasi Teknologi Akuakultur. Pusat Riset Perikanan Budidaya. Jakarta Selatan.

Prijatna, D., Handarto., Yosua, A. (2018). Rancangan Bangun Pemberi Pakan Ikan Otomatis. Jurnal Teknotan, 12(1). 30-35.

Subandiyono \& Hastuti, S. (2011). Buku Ajar Nutrisi Ikan. Badan Penerbit Universitas Diponegoro : Semarang.

Subandiyono, Muhammad, A. R. H., \& Ponandoyo (2014). Pengaruh Frekuensi Pemberian Pakan terhadap Pertumbuhan dan Kelulushidupan Benih Tawes (Puntius javanicus). Journal of Aquaculture Management and Technology, 3(4). 67-74.

Wardhani, L. K, Safrizal, M., \& Chariri, A. (2011). Optimasi Komposisi Bahan Pakan pada Ikan Air Tawar menggunakan metode multi-objective genetic algorithm. dalam Seminar Nasional Aplikasi Teknologi Informasi (SNATI) di Yogyakarta Tanggal 17-18 Juni. 112-117.

Yusuf, D. C. (2018). Mesin Pakan Otomatis pada Budidaya Ikan Air Tawar Menggunakan Sms Berbasis Mikrokontroler Arduino Mega. Jurnal Elektronik Pendidikan Teknik Elektronika, 7(1). 1-8. 